\title{
Ship-to-ship interaction during overtaking operation in shallow water
}

\author{
"Zhi-Ming Yuan, Shi He, Paula Kellett, Atilla Incecik, Osman Turan, Evangelos Boulougouris \\ Department of Naval Architecture, Ocean and Marine Engineering \\ University of Strathclyde, Glasgow, UK
}

\begin{abstract}
Hydrodynamic interaction continues to be a major contributory factor in marine casualties and hazardous incidents, in particular in the case of overtaking operations. The situation becomes even worse when the overtaking operation occurs in shallow and narrow channels where the interaction can cause the vessels to collide and, in one case has caused the capsizal of the smaller vessel with loss of life. The aim of this paper is to propose a methodology, as well as to discuss the development of a numerical program, to predict the ship-to-ship interaction during overtaking operations in shallow water. Since the vessels involved in the present study have different forward speeds, an uncoupled method will be used to solve the boundary value problem. The in-house multi-body hydrodynamic interaction program MHydro, which is based on the 3D Rankine source method, will be used and extended here to investigate the interactive forces and wave patterns between two ships during an overtaking operation. The present calculations are compared with model test results as well as published CFD calculations. Very satisfactory agreement has been obtained, which indicates that the proposed methodology and developed program are successfully validated to predict the hydrodynamic interaction between two ships advancing in confined waters. The discussions also highlight the speed effects.
\end{abstract}

Key words: Hydrodynamic interaction; Rankine source method; shallow water; forward speed; overtaking; lightering operation.

\section{Introduction}

Scenarios involving the hydrodynamic interaction between vessels vary vastly. But the interaction is most likely to prove dangerous when two vessels are involved in an overtaking operation. One possible outcome is that the vessel being overtaken may take a sheer into the course of the other. Another possibility is that when the vessels are abeam of one another, the bow of each vessel may turn away from the bow of the other causing their respective sterns to swing towards each other. This may also be accompanied by an overall strong attractive force between the two vessels due to the reduced pressure between the underwater portions of the hulls. There are also other possible effects which will depend on

\footnotetext{
${ }^{*}$ Corresponding author at: Dep. of Naval Architecture, Ocean \& Marine Engineering, University of Strathclyde. Henry Dyer Building, G4 OLZ, Glasgow, UK.

Tel: + 44 (0)141548 3308. Fax: +44 (0)141552 2879 .

E-mail address: zhiming.yuan@strath.ac.uk
} 
a number of factors including the size of one vessel relative to the other, with the smaller of the two vessels feeling the greater effect (MCA, 2002).

The importance of hydrodynamic interaction has been realized during the past decades. According to the method adopted here, the studies on overtaking operations can be divided into two categories; the experimental and the numerical ones. The first investigation was based on an experimental approach. Newton (1960) carried out model tests of two ships during overtaking manoeuvres in deep water. Two ships meeting and overtaking in a narrow channel were investigated by Müller (1967). Brix (1993) developed an approximate empirical method to estimate the maximum values of longitudinal and transverse forces during overtaking operations. His method was only valid for overtaking manoeuvres where the water depth effect is not considered, and for a limiting ship length ratio. Extensive automated tests on hydrodynamic interaction of two ships during overtaking, passing by and encountering operations were carried out by Vantorre et al. (2002). A special two-carriage experimental set-up was used and time histories of the surge and sway interaction forces and of the yaw moment for various lateral distances and speed values were measured. Based on the large volume of data, a simple approximated empirical method for estimating peak values of the interaction forces was proposed. More recently, Lataire et al. $(2009 ; 2012)$ conducted a captive model test program to investigate ship lightering operation. Particular attention was paid to the forces and moments induced on the service ship by the proximity of the ship to be lightered. A mathematical model of lightering manoeuvres for both the service ship and the ship to be lightered was derived.

Although model tests can provide more reliable and convincing results than the numerical simulations, the time and funds invested in model tests are also considerable. The amount of independent parameters involved in ship-to-ship interaction problems is also very large, which adds to the difficulties of the model set-up. Besides, the overtaking operation places a very high requirement on the test facility, since the ships involved in the model tests have different forward speeds. As the performance capabilities of the computer increase rapidly, more researchers prefer to establish a reliable numerical method to investigate the complex phenomenon between two ships during overtaking operations. In the early stage, a numerical program was developed based on a 2D method. Tuck and Newman (1974) developed a slender-ship method for calculating sway forces and yaw moments for two ships moving along parallel courses in deep water. The ships could each have arbitrary speeds, so the solution was valid for headon encounters, overtaking manoeuvres, or for one ship stationary. A similar approach was applied by Yeung (1978), and the method of matched asymptotic expansions was complemented in his study. His method took the Kutta condition on the aft part of the hull into consideration and improved the computational effort, but it heavily underestimated the sway forces and yaw moments in the most interesting case of a small separation between the hulls. Yeung's method was extended by Gourlay (2009) to calculate the sinkage and trim of two ships during an overtaking manoeuvre. Numerical calculations showed that the maximum bow, stern and LCF sinkage in an overtaking manoeuvre were 
very similar to the case of ships passing from opposing directions. Fang and Kim (1986) utilized a 2D procedure, including the hydrodynamic interaction and an integral equation method, to predict the coupled motions between two ships advancing in oblique seas. Varyani et al. $(1998,2002)$ also used a 2D method to calculate the interaction forces acting on two or more ships meeting in restricted waters. The main conclusion drawn from these works on 2D methods is that even a very crude approximation of the ship's hull can provide good estimates for the interaction forces at least in some situations that the ship's hull is slender. However, the 3D effects were neglected or accounted for by means of a blockage coefficient.

In order to improve the accuracy of the prediction, a 3D method is required. Chen and Fang (2001) extended Fang's 2D method (Fang and Kim, 1986) to 3D. It was found that the hydrodynamic interactions calculated by the $3 \mathrm{D}$ method were more reasonable in the resonance region, where the responses were not as significant as predicted by the 2D method. Söding and Conrad (2005) investigated the overtaking manoeuvres by means of model experiments and numerical calculations using two different Rankine source free-surface potential solvers. Unfortunately they didn't provide details about the model test set-up and numerical method. Xu and Faltinsen (2011) developed a 3D Rankine source method to predict the hydrodynamic interactions between two ships advancing in waves. Within the framework of the Green function, $\mathrm{Xu}$ and Dong (2013) developed a 3D translating-pulsating (3DTP) source method to calculate wave loads and free motions of two ships advancing in waves. Their method was limited to solve the ship-to-ship problem in deep water, and the free surface boundary was assumed to be linear. Most recently, Yuan et al. (2014a; 2014b) developed a 3D Rankine source panel method to investigate the hydrodynamic interactions between two ships travelling in shallow water. Here a new modified Sommerfeld radiation condition (Yuan et al., 2014c) was used, which was applicable to a wide range of forward speeds, including the very low forward speed problem where the parameter $\tau\left(\tau=\omega_{e} u / g\right.$, $\omega_{e}$ is the encounter frequency, $u$ is the forward speed, and $g$ is the gravitational acceleration) is smaller than 0.25 . Their method was validated through model experiments and a very satisfactory agreement was obtained. The main conclusion drawn from these works on the 3D potential flow method is that the prediction of ship motions is reasonable except for the roll motion, and the resonance in the gap between the two vessels can be captured. However, most of the works can only solve the boundary value problem based on the assumption that the two vessels are travelling parallel with the same forward speed. Therefore, these studies cannot simulate the ship-to-ship interaction during overtaking operations.

Finally, the viscous method, typically the Reynolds Averaged Navier-Stokes (RANS) method, has gradually been enhanced and shown to be able to produce promising and comprehensive predictions of ship-to-ship interaction. Chen et al. (2002) carried out extensive computations of ship-to-ship interaction by an unsteady RANS method. The method satisfactorily predicted the ship-to-ship head-on encounter and overtaking motions in shallow water and restricted navigation channels, and also the effects of moving ships on a ship moored next to a pier. Zou and Larsson (2013) used a steady state Reynolds 
Averaged Navier-Stokes solver to predict the ship-to-ship interaction during a lightering operation in shallow water. They validated their method through the model tests carried out by Lataire et al. (2009). They also calculated the forces on the vessels with varying relative longitudinal or transverse position. But the process of the lightering operation in their study was assumed to be quasi-static, and the speed of the vessels was kept as the same value. Wang and Zou (2014) used ANSYS FLUENT software to simulate the unsteady viscous flow around a ship passing through the Pierre Vandamme Lock, with a ship berthed near the lock entrance. They applied a dynamic mesh method and sliding interface technique to deal with the relative motion between the passing ship and the lock. The main conclusion drawn from these works is that the viscous method can provide a satisfactory prediction of the forces, as well as the sinkage and trim on both ships. The viscous effects can be fully simulated and as a result, the prediction of the resistance could be more reliable compared with that from potential flow methods. Besides, the influence from the rudder and propeller can also be simulated by using the viscous method, which is impossible in potential flow methods. But it doesn't mean this method is perfect. The viscous method is very time consuming, and it relies highly on the performance of the computer. For the shipto-ship interaction problem, the computational domain is always asymmetric. It requires a large amount of time to simulate a single case. But, as mentioned before, the amount of independent parameters involved in ship-to-ship interaction problems are always very large. In order to establish a clear view on how these factors influence each other, the simulations may involve considerable case studies. Therefore, the viscous method still needs to be enhanced before it can be applied in engineering practice.

The aim of this paper is to propose a methodology, as well as to discuss the development of a numerical program, to predict the ship-to-ship interaction during overtaking operations in shallow water. The method adopted here is based on 3D Rankine source potential flow theory and therefore can save a lot of computational effort in comparison to a viscous approach. In the previous studies on ship-to-ship interaction problem using potential flow method, the so-called double-body flow was applied on the free surface boundary condition, which can be expressed as

$$
\frac{\partial \varphi}{\partial n}=0, \quad \text { on the undisturbed free surface }
$$

where $\varphi$ is the steady perturbation potential. Since the forward speed $u$ is not included in the free surface boundary condition, the speed of the two vessels can be arbitrary. But in the present study, the wellknown Kelvin free surface condition (Newman, 1976) will be used, which can be written as

$$
u^{2} \frac{\partial^{2} \varphi}{\partial x^{2}}+g \frac{\partial \varphi}{\partial z}=0, \quad \text { on the undisturbed free surface }
$$

where $\mathrm{g}$ is the acceleration due to gravity. The first term in Eq. (2) includes the influence from the forward speed $u$. During the overtaking process, the two ships always have different speeds. Therefore, the corresponding boundary value problem should be modified. In order to account for the different 
speeds appearing in the free surface boundary condition, we propose an uncoupled method. This method will be applied to our in-house developed multi-body hydrodynamic interaction program MHydro (Yuan et al., 2014b) to investigate the interactive forces and wave patterns between two ships during an overtaking process.

\section{Mathematical formulation}

\subsection{Coordinate system}

The corresponding right-handed coordinate systems are shown in Figure 1. The body coordinate systems $o_{a}-x_{a} y_{a} z_{a}$ and $o_{b}-x_{b} y_{b} z_{b}$ are fixed on Ship_a and Ship_b respectively with their origins on the mean free surface at midships. $o_{a}-z_{a}$ and $o_{b}-z_{b}$ are both positive upwards. $O-X Y Z$ is the earth-fixed coordinate system with its origin located on the calm free surface and $O Z$ axis positive upwards. $d t$ and $d l$ denote the transverse and longitudinal distance between the two ships respectively, while $u_{a}$ and $u_{b}$ are the forward speeds of Ship_a and Ship_b.

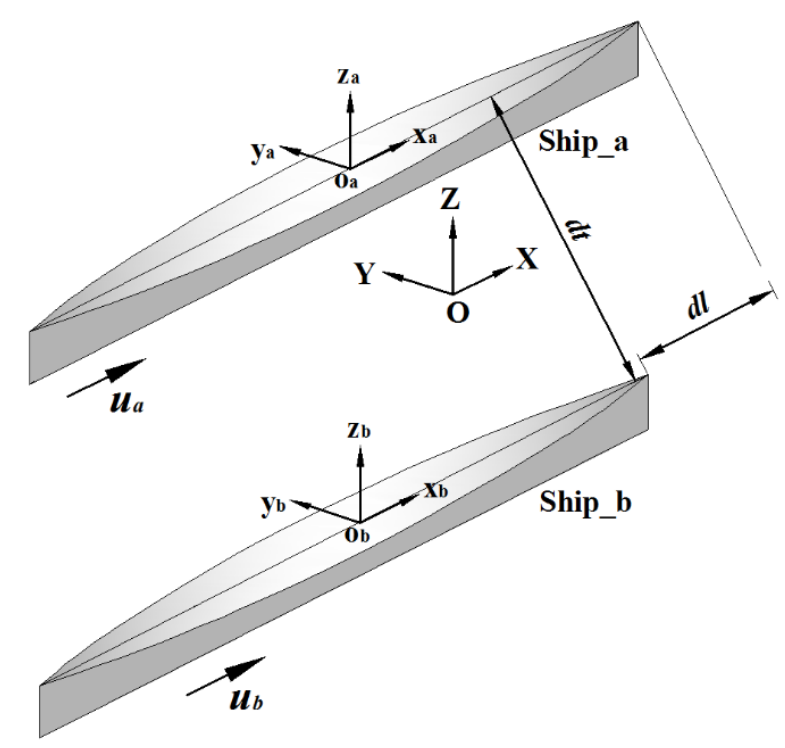

Figure 1 An example vessels and coordinate system.

\subsection{The boundary value problem}

When a ship advances at constant speed in water, it will generate steady waves and induce the so-called wave-making resistance. It is assumed that the fluid is incompressible and inviscid and the flow is irrotational. A velocity potential $\varphi_{T}=u x+\varphi$ is introduced and $\varphi$ satisfies the Laplace equation

$$
\nabla^{2} \varphi=0 \quad \text { in the fluid domain }
$$

Following Newman (1976), the nonlinear dynamic free-surface condition on the disturbed free surface can be expressed as 


$$
u \frac{\partial \varphi}{\partial x}+\frac{1}{2}\left[\left(\frac{\partial \varphi}{\partial x}\right)^{2}+\left(\frac{\partial \varphi}{\partial y}\right)^{2}+\left(\frac{\partial \varphi}{\partial z}\right)^{2}\right]+g \zeta=0, \quad \text { on } z=\zeta(x, y)
$$

The kinematic free-surface condition is

$$
u \frac{\partial \zeta}{\partial x}-\frac{\partial \varphi}{\partial z}+\frac{\partial \varphi}{\partial y} \frac{\partial \zeta}{\partial y}+\frac{\partial \varphi}{\partial x} \frac{\partial \zeta}{\partial x}=0, \quad \text { on } z=\zeta(x, y)
$$

The first approximation is based on the linear free surface conditions on the undisturbed water surface. By neglecting the nonlinear terms in Eq. (4) and (5), we can obtain the linear classic free surface boundary condition in the form of Eq. (2).

For the ship-to-ship with same forward speed problem, the body surface boundary condition can be written as

$$
\frac{\partial \varphi}{\partial n}=u \cdot n_{1}, \quad \text { on the wetted body surface }
$$

where $\overrightarrow{\mathbf{n}}=\left(n_{1}, n_{2}, n_{3}\right)$ is the unit normal vector inward on the wetted body surface of Ship_a and Ship_b. The boundary condition on the sea bottom and side walls can be expressed as

$$
\frac{\partial \varphi}{\partial n}=0, \quad \text { on } z=-h \text { and side walls }
$$

Besides, a radiation condition is imposed on the control surface to ensure that the waves vanish upstream of the disturbance.

Eq. (2), (3), (6), (7) and a radiation condition constitute the basic boundary value problem of two ships with the same speed. Since the potential $\varphi$ can be solved by a single boundary value problem, this method can be referred to as the coupled method. However, the speed of the ships is different during an overtaking process. The coupled method is not appropriate due to the first term in Eq. (2). In order to deal with the different forward speeds, we propose a new uncoupled method. The potential $\varphi$ can be divided into two components

$$
\varphi=\varphi_{a}+\varphi_{b}
$$

$\varphi_{a}$ is the potential produced by the case that Ship_a is moving with $u_{a}$ while Ship_b is stationary. According to the linear theory, it satisfies the Laplace equation. The boundary value problem for $\varphi_{a}$ can be written as 
$\nabla^{2} \varphi_{a}=0, \quad$ in the fluid domain

$\frac{\partial \varphi_{a}}{\partial n}=u_{a} \cdot n_{1}$, on wet body surface of Ship_a

$\frac{\partial \varphi_{a}}{\partial n}=0, \quad$ on wet body surface of Ship_b

$u_{a}^{2} \frac{\partial^{2} \varphi_{a}}{\partial x^{2}}+g \frac{\partial \varphi_{a}}{\partial z}=0$, on undisturbed free surface

$\frac{\partial \varphi_{a}}{\partial n}=0$, on sea bottom and side walls

Similarly, the $\varphi_{b}$ is defined as the potential produced by the case that Ship_b is moving with $u_{b}$ while Ship_a is stationary. The boundary value problem for $\varphi_{b}$ can be written as

$$
\begin{aligned}
& \nabla^{2} \varphi_{b}=0, \quad \text { in the fluid domain } \\
& \frac{\partial \varphi_{b}}{\partial n}=u_{b} \cdot n_{1}, \quad \text { on wet body surface of Ship_b } \\
& \frac{\partial \varphi_{b}}{\partial n}=0, \quad \text { on wet body surface of Ship_a } \\
& u_{b}^{2} \frac{\partial^{2} \varphi_{b}}{\partial x^{2}}+g \frac{\partial \varphi_{b}}{\partial z}=0, \quad \text { on undisturbed free surface } \\
& \frac{\partial \varphi_{b}}{\partial n}=0, \text { on sea bottom and side walls }
\end{aligned}
$$

$\varphi_{a}$ and $\varphi_{b}$ can be obtained by solving the boundary value problem in Eq. (9) and (10). The details about how to discretise the boundaries numerically by using the 3D Rankine source method can be found in Yuan et al. (2014c). The same procedure will be applied in the present study.

\subsection{Forces and wave elevation}

Once the unknown potential $\varphi$ is solved, the pressure on Ship_a and Ship_b can be obtained from Bernoulli's equation:

$$
\begin{aligned}
& p_{a}=\rho u_{a} \frac{\partial \varphi}{\partial x}-\frac{1}{2} \rho\left[\left(\frac{\partial \varphi}{\partial x}\right)^{2}+\left(\frac{\partial \varphi}{\partial y}\right)^{2}+\left(\frac{\partial \varphi}{\partial z}\right)^{2}\right] \\
& p_{b}=\rho u_{b} \frac{\partial \varphi}{\partial x}-\frac{1}{2} \rho\left[\left(\frac{\partial \varphi}{\partial x}\right)^{2}+\left(\frac{\partial \varphi}{\partial y}\right)^{2}+\left(\frac{\partial \varphi}{\partial z}\right)^{2}\right]
\end{aligned}
$$

where $\rho$ is the fluid density. The forces on Ship_a and Ship_b can be written as

$$
\begin{aligned}
F_{i}^{a} & =\iint_{S_{a}} p_{a} n_{i} d s \\
F_{i}^{b} & =\iint_{S_{b}} p_{b} n_{i} d s
\end{aligned}
$$


where

$$
n_{i}= \begin{cases}\overrightarrow{\mathbf{n}}, & i=1,2,3 \\ \overrightarrow{\mathbf{x}} \times \overrightarrow{\mathbf{n}}, & i=4,5,6\end{cases}
$$

The mean sinkage $\sigma$ and trim $\tau$ can be written as

$$
\begin{aligned}
& s=F_{3} / \rho g A_{w} \\
& t=F_{5} / \rho g I_{w}
\end{aligned}
$$

Where $A_{w}$ is the water plane area and $I_{w}$ is second moment of the water plane about the $y$-axis.

The wave elevation on the free surface can then be obtained from the dynamic free surface boundary condition in the form

$$
\begin{aligned}
& \zeta_{a}=\frac{u_{a}}{g} \frac{\partial \varphi_{a}}{\partial x}-\frac{1}{2 g}\left[\left(\frac{\partial \varphi_{a}}{\partial x}\right)^{2}+\left(\frac{\partial \varphi_{a}}{\partial y}\right)^{2}+\left(\frac{\partial \varphi_{a}}{\partial z}\right)^{2}\right] \\
& \zeta_{b}=\frac{u_{b}}{g} \frac{\partial \varphi_{b}}{\partial x}-\frac{1}{2 g}\left[\left(\frac{\partial \varphi_{b}}{\partial x}\right)^{2}+\left(\frac{\partial \varphi_{b}}{\partial y}\right)^{2}+\left(\frac{\partial \varphi_{b}}{\partial z}\right)^{2}\right]
\end{aligned}
$$

The total wave elevation can be written as

$$
\zeta=\zeta_{a}+\zeta_{b}
$$

\section{Validation studies}

\subsection{Validations of two ships with the same forward speed}

The present uncoupled method is included in our in-house developed multi-body hydrodynamic interaction program MHydro to investigate the interactive forces and wave patterns between a very large crude oil carrier (referred as KVLCC2 hereafter) and an Aframax tanker (referred as Aframax hereafter) with the same forward speed in the shallow water. The convergence study for MHydro can be found in Yuan et al. (2014b). In the present study, we distribute twice as many panels as in the previous study to ensure computational accuracy.

\subsubsection{Ship models}

The model tests for ship-to-ship with the same forward speed were carried out at the Towing Tank for Manoeuvres in Shallow Water (co-operation Flanders Hydraulics Research- Ghent University) in Antwerp, Belgium by Lataire et al. (2009). The main dimensions of the tank are Length $88 m \times$ Breadth $7 \mathrm{~m} \times$ Depth $0.5 \mathrm{~m}$. The ship to be lightered is a KVLCC 2 scaled model with scale factor $1 / 75$. The 
service ship used for model testing is an Aframax tanker with the same scale factor. The main particulars of the KVLCC2 and Aframax models are shown in Table 1.

Table 1 Main particulars of KVLCC2 and Aframax models.

\begin{tabular}{lcc}
\hline & KVLCC2 & Aframax \\
\hline Length between perpendicular $(m)$ & $L_{a}=4.267$ & $L_{b}=3.085$ \\
Breadth $(m)$ & $B_{a}=0.773$ & $B_{b}=0.560$ \\
Draft $(m)$ & $T_{a}=0.277$ & $T_{b}=0.100$ \\
Displacement $\left(m^{3}\right)$ & $V_{a}=0.741$ & $V_{b}=0.139$ \\
\hline
\end{tabular}

\subsubsection{Test matrix}

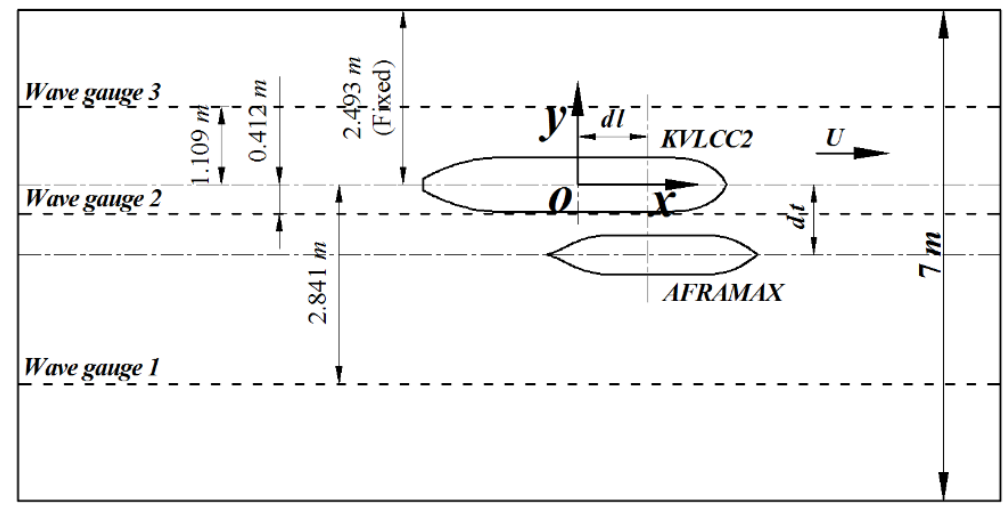

Figure 2 Model test set-up

The model test set-up is shown in Figure 2. During the captive model tests, the ship models are free to heave and pitch but are rigidly connected to the carriage in terms of the other degrees of freedom. There are three wave gauges arranged at different values of $y$, as shown in Figure 2, to measure the corresponding wave profiles. Six independent test conditions were carried out, and only two typical shallow water tests are used here to validate our numerical program. The test conditions for these two tests are listed in Table 2. The Froude number is defined as $F_{n}=u / \sqrt{g L_{b}}$. 
Table 2 Two typical test conditions

\begin{tabular}{lcc}
\hline & Test 1 & Test 2 \\
\hline Water depth $h(m)$ & 0.374 & 0.475 \\
Draft of KVLCC2 $(m)$ & 0.277 & 0.277 \\
Draft of Aframax $(m)$ & 0.100 & 0.100 \\
$h / T a$ & 1.350 & 1.715 \\
Speed $(\mathrm{m} / \mathrm{s})$ & 0.237 & 0.356 \\
Froude number $F_{n}$ & 0.043 & 0.065 \\
Transverse distance $d t(m)$ & 0.9995 & 0.9995 \\
$d t / B_{b}$ & 1.785 & 1.785 \\
Longitudinal distance $d l(m)$ & 0 & 1.543 \\
$d l / L_{b}$ & 0 & 0.5 \\
\hline
\end{tabular}

\subsubsection{Numerical models}

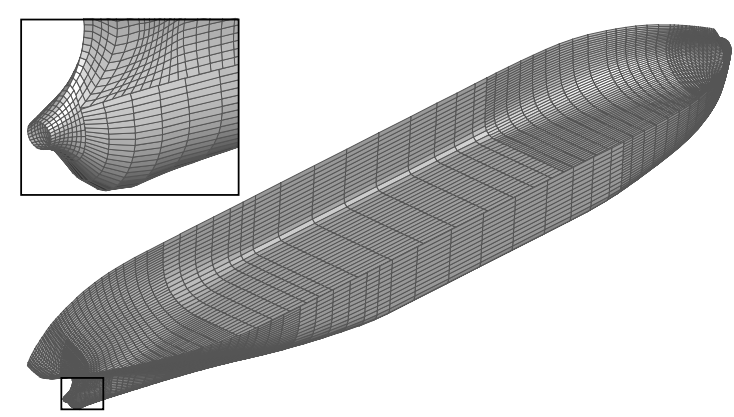

(a)

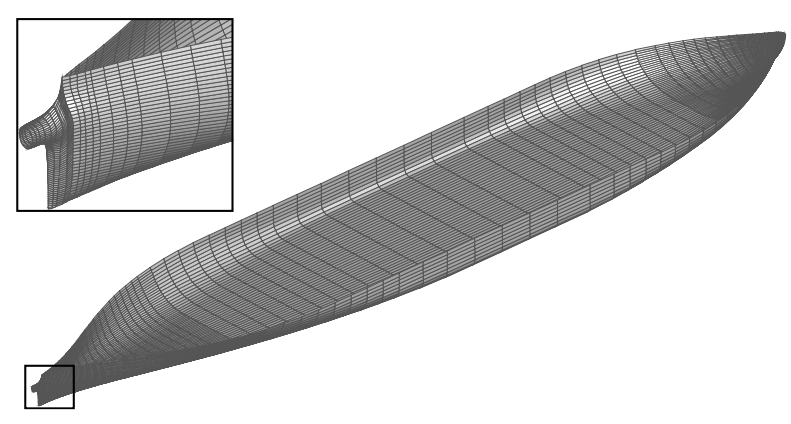

(b)

Figure 3 Mesh distribution on wet body surface. (a) KVLCC2 model; (b) Aframax model.

There are 14040 panels (8080 on KVLCC2 and 6020 on Aframax) distributed on the body surface, which is shown in Figure 3. More panels are distributed in the bow and stern areas in order to model the complex geometry in these parts. The panel distribution on the free surface is shown in Figure 4, from which we can see that the panel distribution in the bow and stern regions is very dense. The mesh size increases as the panel radiates from the body surface to the computational borders, since the pressure distribution on the body surfaces is highly related to the surrounding fluid. The free surface is truncated at $1.5 L_{a}$ upstream and $3 L_{a}$ downstream. There are 13875 panels distributed on the free surface. Side walls are fully modelled according to the model test set-up and they are discretized to 760 panels. There are 28675 panels distributed on the whole computational domain. 


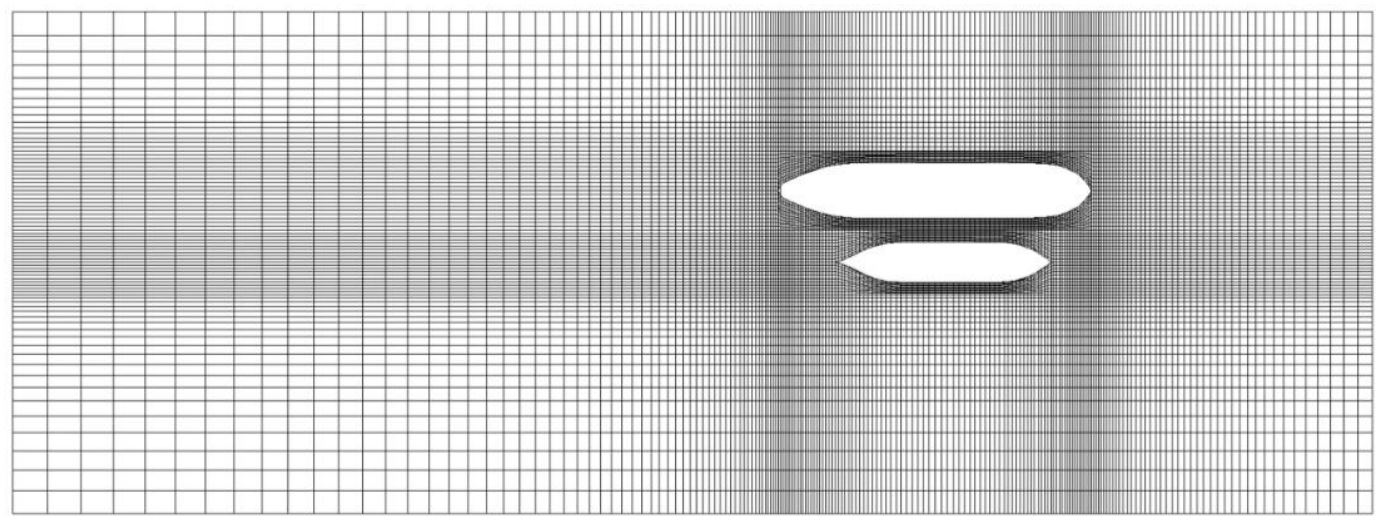

Figure 4 Mesh distribution on free surface.

\subsubsection{Wave elevation}

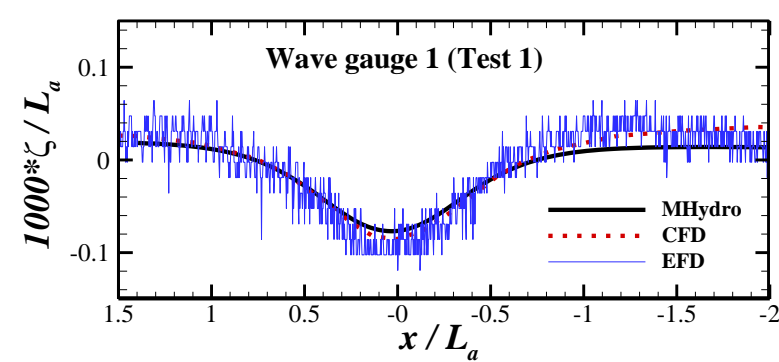

(a)

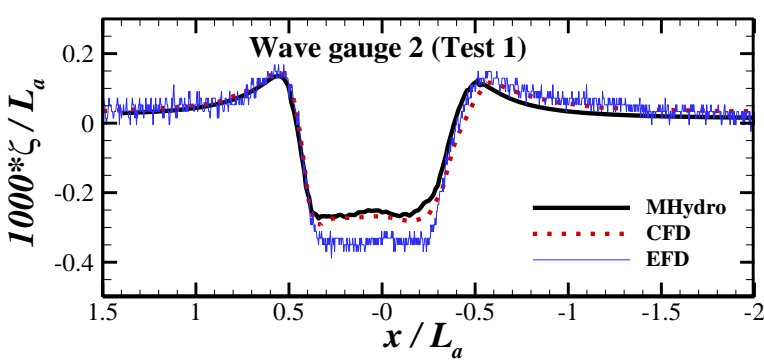

(b)

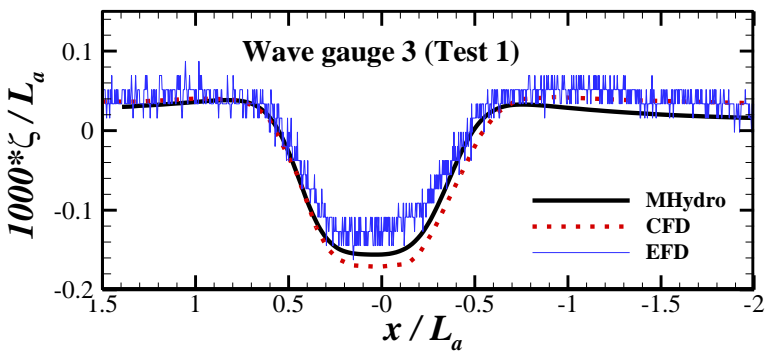

(c)

Figure 5 Wave profiles of Test 1. (a) Wave gauge 1; (b) wave gauge 2; (3) wave gauge 3.

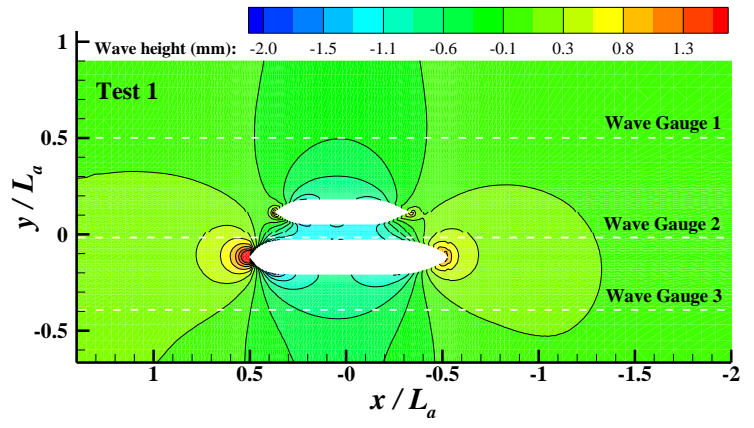

(a)

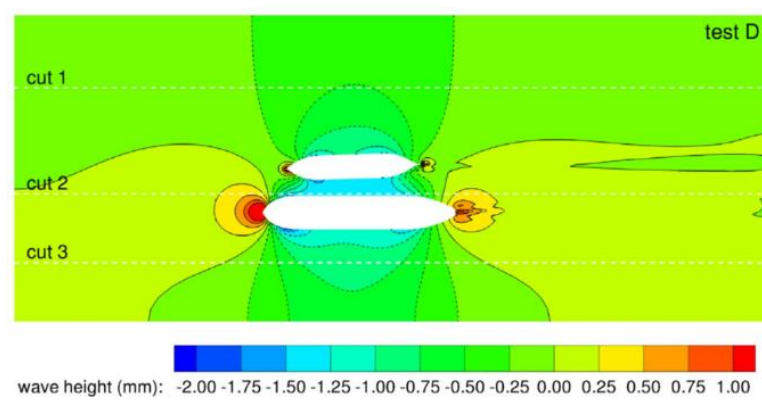

(b)

Figure 6 Wave patterns of Test 1. (a) Present calculation; (b) CFD results from Zou and Larsson (2013).

Figure 5 shows the wave profiles measured from three wave gauges. The present results from MHydro and CFD results from SHIPFLOW (Zou and Larsson, 2013) are also presented. The positive $x$ values 
represent the upstream part of the domain. It can be found from these figures that the present predictions agree with the measurements and CFD results very well at wave gauge 1 and 3 . At wave gauge 2, the present method under-estimates the wave elevation between the two ships. But it matches the CFD method very well, which indicates that viscous effects on the wave elevation are very small. These waves will account for the so-called wave-making resistance. The wave pattern of Test 1 obtained from MHydro is shown in Figure 6 (a) and the CFD results (Zou and Larsson, 2013) are shown in Figure 6 (b). The label 'test D' in the right-top of Figure 6 (b) corresponds to test conditions of Test 1 in the present study. Generally, a very good agreement has been obtained between these two programs. Only very small discrepancies can been found in the stern areas of both ships, which is due to the influence from the propeller. In the present calculation based on the potential flow theory, the influence from the propeller has been neglected. The wave profiles and wave patterns of Test 2 are shown in Figure 7 and Figure 8. Similar conclusions can be drawn from Test 1 . Through these validations it can be concluded that the present method can be used to predict the wave elevation when a ship overtakes another in shallow water.

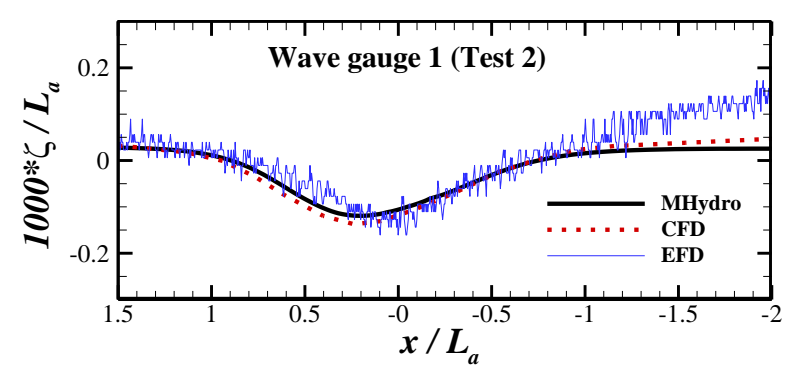

(a)

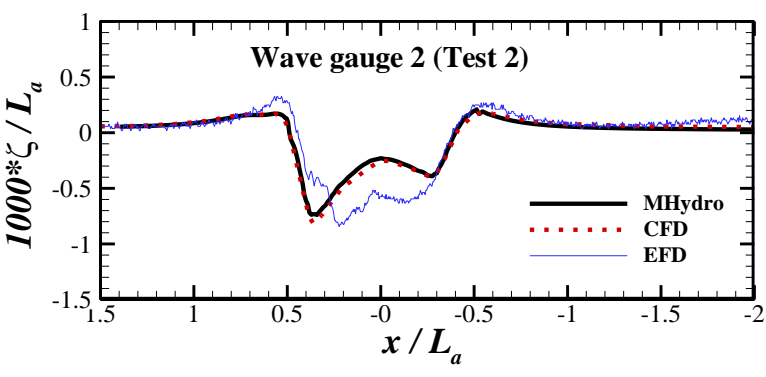

(b)

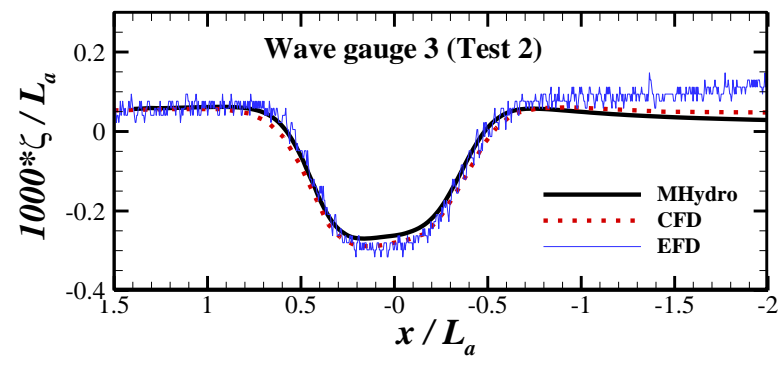

(c)

Figure 7 Wave profiles of Test 2. (a) Wave gauge 1; (b) wave gauge 2; (3) wave gauge 3. 


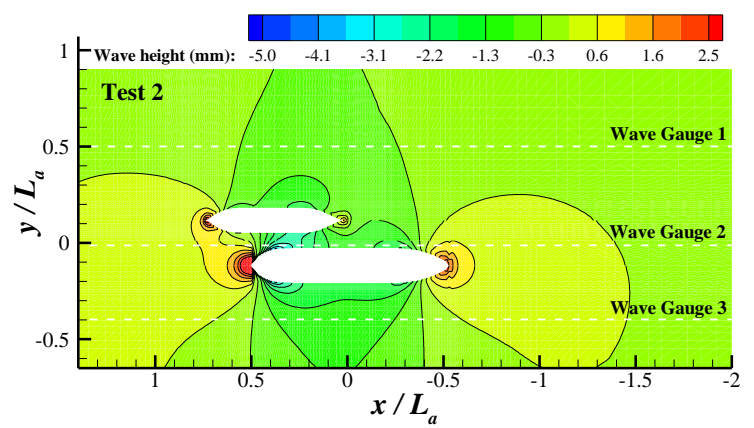

(a)

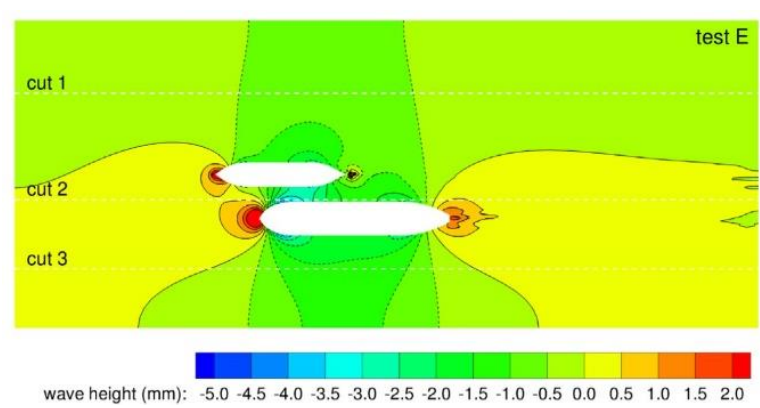

(b)

Figure 8 Wave patterns of Test 2. (a) Present calculation; (b) CFD results from Zou and Larsson (2013).

\subsubsection{Coupled and uncoupled method}

In order to validate the uncoupled method, the same models and test condition from Test 1 (as shown in Table 2) are used. Since the forward speed of the two ships in Test 1 is the same, the coupled method can also be used. The wave elevation on the free surface is calculated by using the coupled and uncoupled methods. Figure 9 shows a comparison of the wave patterns obtained by using these two different methods. In order to make an intuitive comparison, we divide the whole free surface into two parts along the centre line of KVLCC2: the port side part (as shown in Figure 9 (a)) and starboard side part (as shown in Figure 9 (b)). The upper half of each figure shows the wave pattern obtained by using the coupled method of Eq. (2), (3), (6) and (7), and lower half of each figure shows the wave pattern obtained by using the uncoupled method of Eq. (3), (8), (9) and (10). The agreement between these two methods is very good. Figure 10 gives the wave profiles obtained by these two methods. Except for a slight discrepancy in the gap between the two ships, the general agreement is very good, which indicates that the present uncoupled method can be extended to predict the hydrodynamic interaction between ships with different forward speeds.

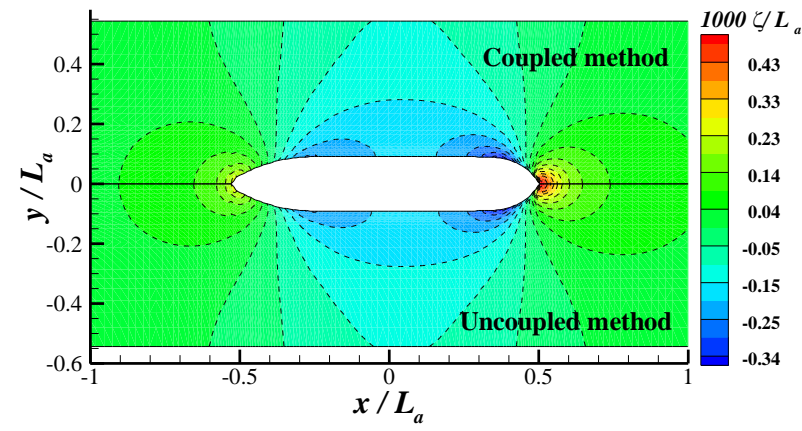

(a)

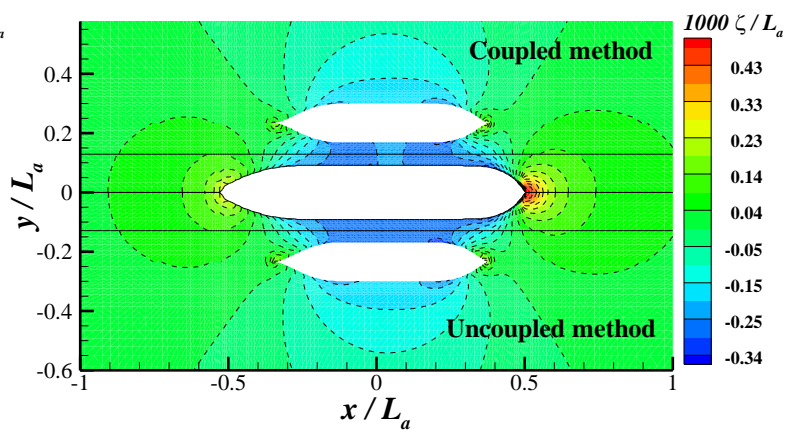

(b)

Figure 9 Wave patterns obtained by different methods. (a) Port of KVLCC2; (b) starboard of KVLCC2. 


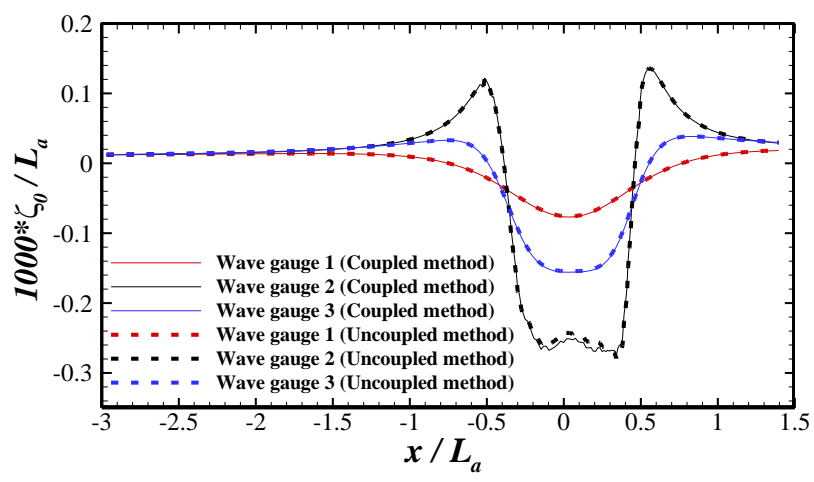

Figure 10 Wave profiles obtained by different methods.

We also examine the wave elevation and the forces on both of the ships at different forward speeds. The wave elevation at point $\mathrm{O}(0,-0.5)$ is calculated and shown in Figure 11 . Very satisfactory agreement between the coupled and uncoupled method can be observed at Froude number ranging from 0 to 0.2. The results in Figure 12 show the forces (or moments), sinkage and trim at different forward speeds. The discrepancy between the coupled and uncoupled method is very small in the full range of Froude number from 0 to 0.2 . In the practice of overtaken manoeuvre in shallow water, the speed of the ships is always restricted to avoid the squat and collision. Therefore, the present uncoupled method based on the linear assumption is a valid method to predict the hydrodynamic properties of two ships during overtaking operation in shallow and narrow water ways. It can also be observed from Figure 12 that the wave-making resistance on the larger ship increases significantly until $F n=0.15$, and then the trend reversed. At $F n=0.2$, the wave-making resistance on both ships are positive. If no action is taken to reduce the engine revolution, the speed of both ships could increase rapidly at $F n>0.15$, which may result in grounding or collision due to the large sinkage, trim and yaw moment. More detailed discussions about the speed effects can be found in the next section.

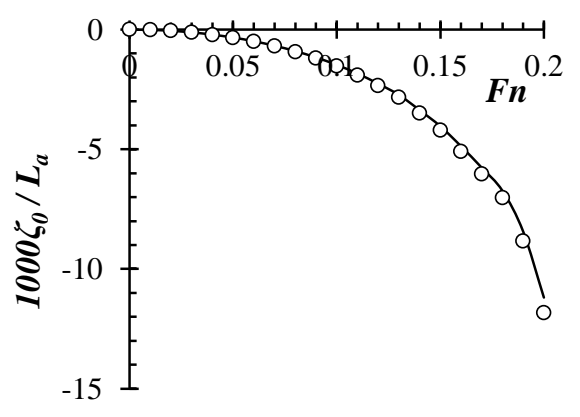

Figure 11 Wave elevation at $\mathrm{O}(0,-0.5)$. $\odot$, Coupled method; -, Uncoupled method. 

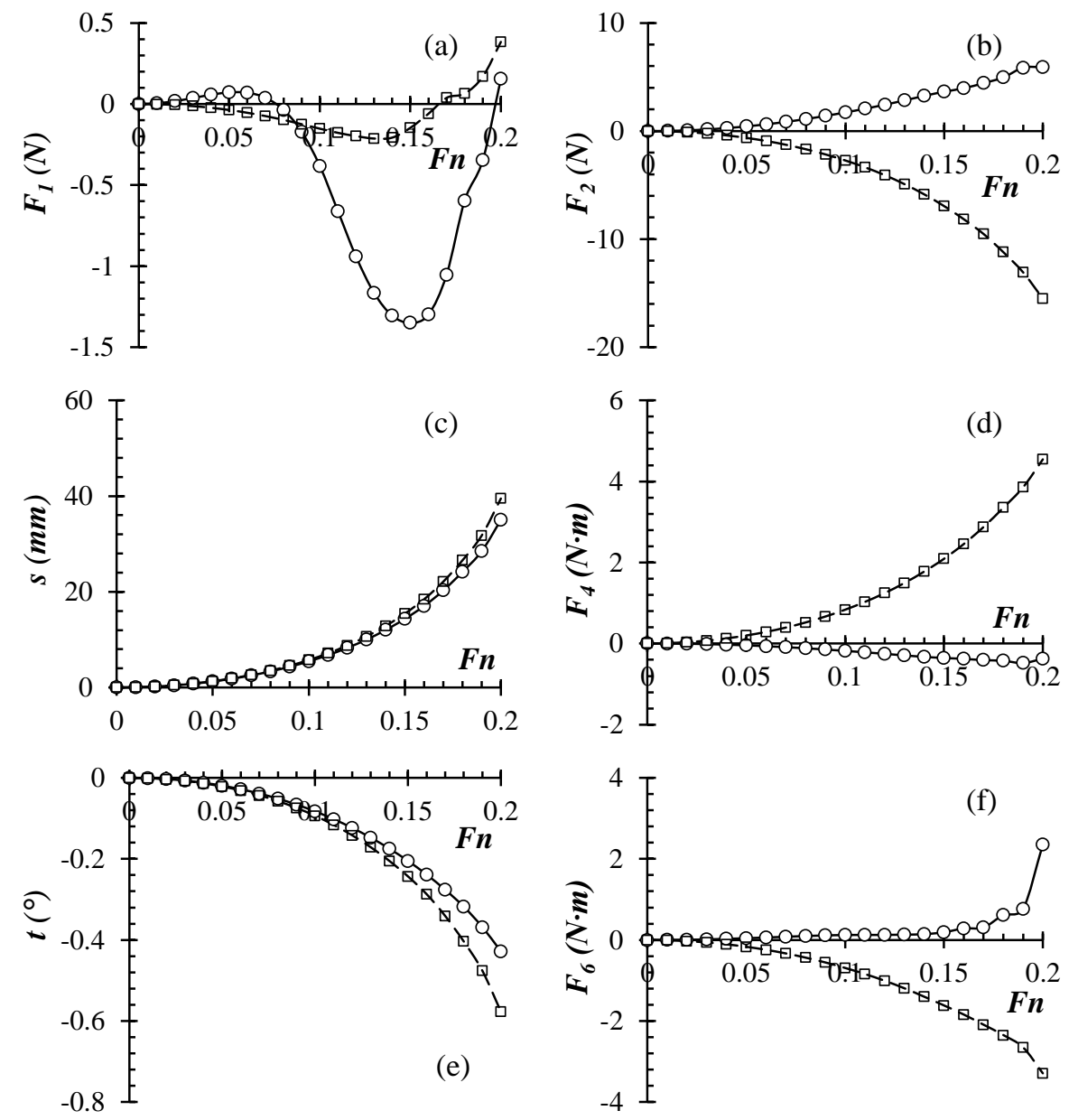

Figure 12. (a) Resistance; (b) sway force; (c) sinkage; (d) roll moment; (e) trim; (f) yaw moment. ○, KVLCC2, coupled method; -, KVLCC2, uncoupled method; $\square$, Aframax, coupled method; - -, Aframax, uncoupled method.

\subsection{Validations of two ships with different forward speeds}

In order to validate the present method and numerical program, another simulation is performed to investigate the ship-to-ship with different forward speeds problem. The model tests used here were carried out by Vantorre, et al. (2002) at the same tank as mentioned in Section 3.1. They installed an auxiliary carriage alongside the main carriage to achieve a different towing speed. They performed a comprehensive test programs based a series of ship models. In the present study, two Esso Osaka models (referred as Model C and Model E hereafter) with scale factor 1/75 are selected to validate the developed method. The main particulars of Model C and Model E in full scale can be found in Table 3.

Table 3 Main particulars of Model C and Model E.

\begin{tabular}{lcc}
\hline & Model E & Model C \\
\hline Length between perpendicular $(m)$ & $L_{a}=286.8$ & $L_{b}=298.8$ \\
Breadth $(m)$ & $B_{a}=46.8$ & $B_{b}=37.8$ \\
Draft $(m)$ & $T_{a}=15.53$ & $T_{b}=13.5$ \\
Block coefficient & $C_{B a}=0.816$ & $C_{B b}=0.843$ \\
\hline
\end{tabular}


In the model test, Model $\mathrm{E}$ was towed by the main carriage at the centre line $(y=0)$ of the tank, while Model $\mathrm{C}$ was towed by the auxiliary carriage. The transverse distance is $d t=B_{b}+0.5 B_{a}$ and the water depth $\mathrm{h}$ is $18.63 \mathrm{~m}$. The forward speed of Model $\mathrm{E}$ is 8 knots in full scale, and Model $\mathrm{E}$ was overtaken by Model $\mathrm{C}$ at the speed of 12 knots. The model test set-up is shown in Figure 13. Figure 14 is the computational domain of the numerical model. The reference coordinate system is fixed on Model E.

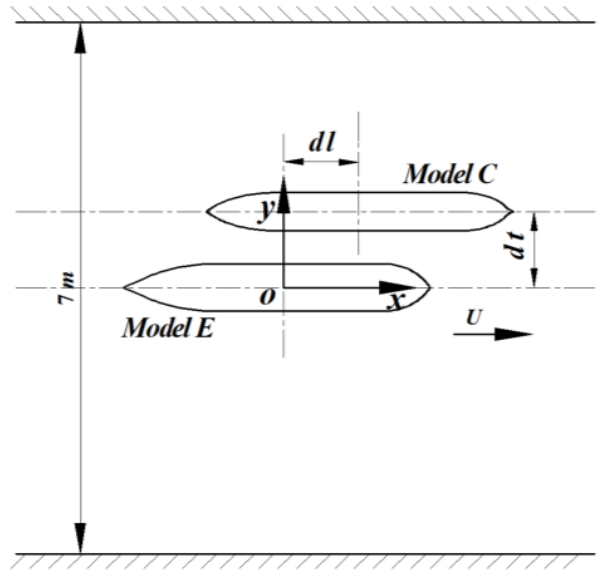

Figure 13 Definition sketch of two ships with different speeds.

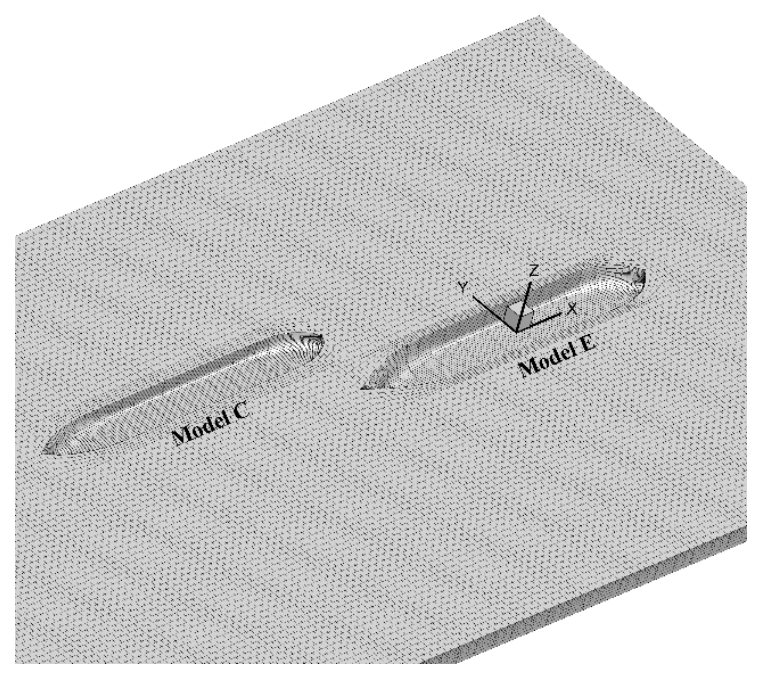

Figure 14 The computational domain of the numerical model. There are 23840 panels distributed on the entire computational domain: 1200 on the body surface of Model C, 1040 on the body surface of Model E, 20640 on the free surface and 960 on the side walls. The computational domain is truncated at $L_{b}$ upstream and $3 L_{b}$ downstream, referred to the upstream ship. 

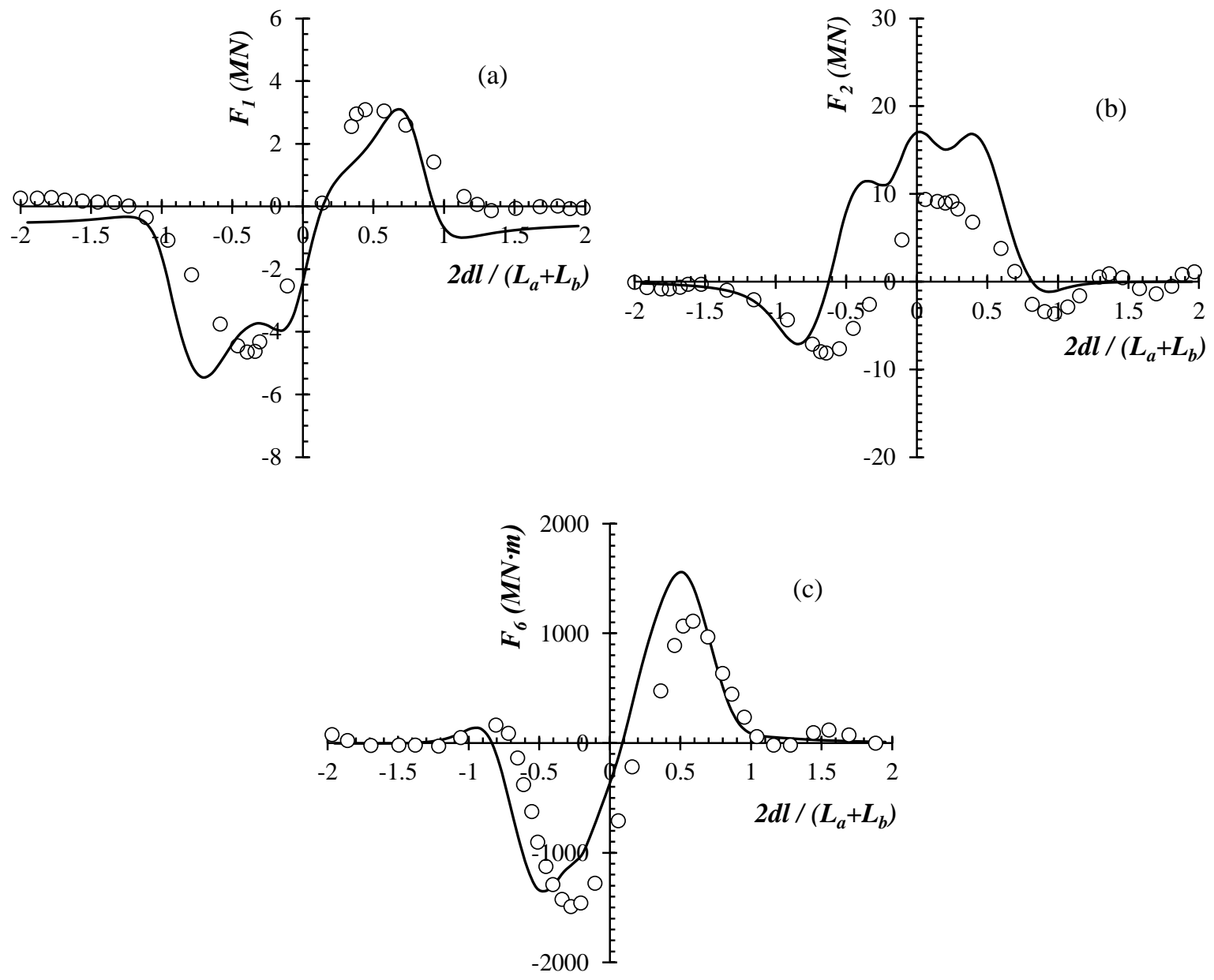

Figure 15. (a) The resistance, (b) the sway force and (c) the yaw moment acting on Model E overtaken by Model C. The negative $x$ values denote that Model $\mathrm{C}$ is in the downstream side of Model $\mathrm{E}$. As Model C moves to the upstream side, the $x$ values become positive. $\circ$, experiment, Vantorre, et al. (2002); -, the present prediction from MHydro.

The force and moment acting on Model E in shallow water are shown in Figure 15. The experimental results are due to Vantorre, et al. (2002). The numerical predictions are obtained by solving the boundary value problem in Eq. (9) and (10). It is worthwhile to note that while the general behaviour of the experimental curves is predicted fairly well, the peak sway force is substantially overestimated, particularly when Model C is "off the shoulder" of Model E. One possible reason could be the neglect of the rudder in the numerical model. It can also be found from Figure 15 (a) that the calculated wavemaking resistance agrees with the experimental measurement very well. The latter one represents the total resistance including the viscus component. It indicates that due to the hydrodynamic interaction between the two ships, the resistance from the pressure integration contributes dominantly to the total resistance even in the low forward speed condition. This is different from the single vessel case (Schultz, 2007). Figure 16 is the results of the force and moment acting on Model $\mathrm{E}$ overtaken by Model $\mathrm{C}$ at different transverse distances. As the clearance between two ships increases, the hydrodynamic interactive forces and moments decrease rapidly. Therefore, in the practice of overtaking operation, the transverse distance between two ships should be strictly controlled as largely as possible, in order to minimize the hydrodynamic interaction. However, in some confined waterways, it is impossible to 
increase the clearance due to the bank effects. In this case, the alternative solution to minimize the hydrodynamic interaction is to reduce the speed, which will be discussed in the next section.
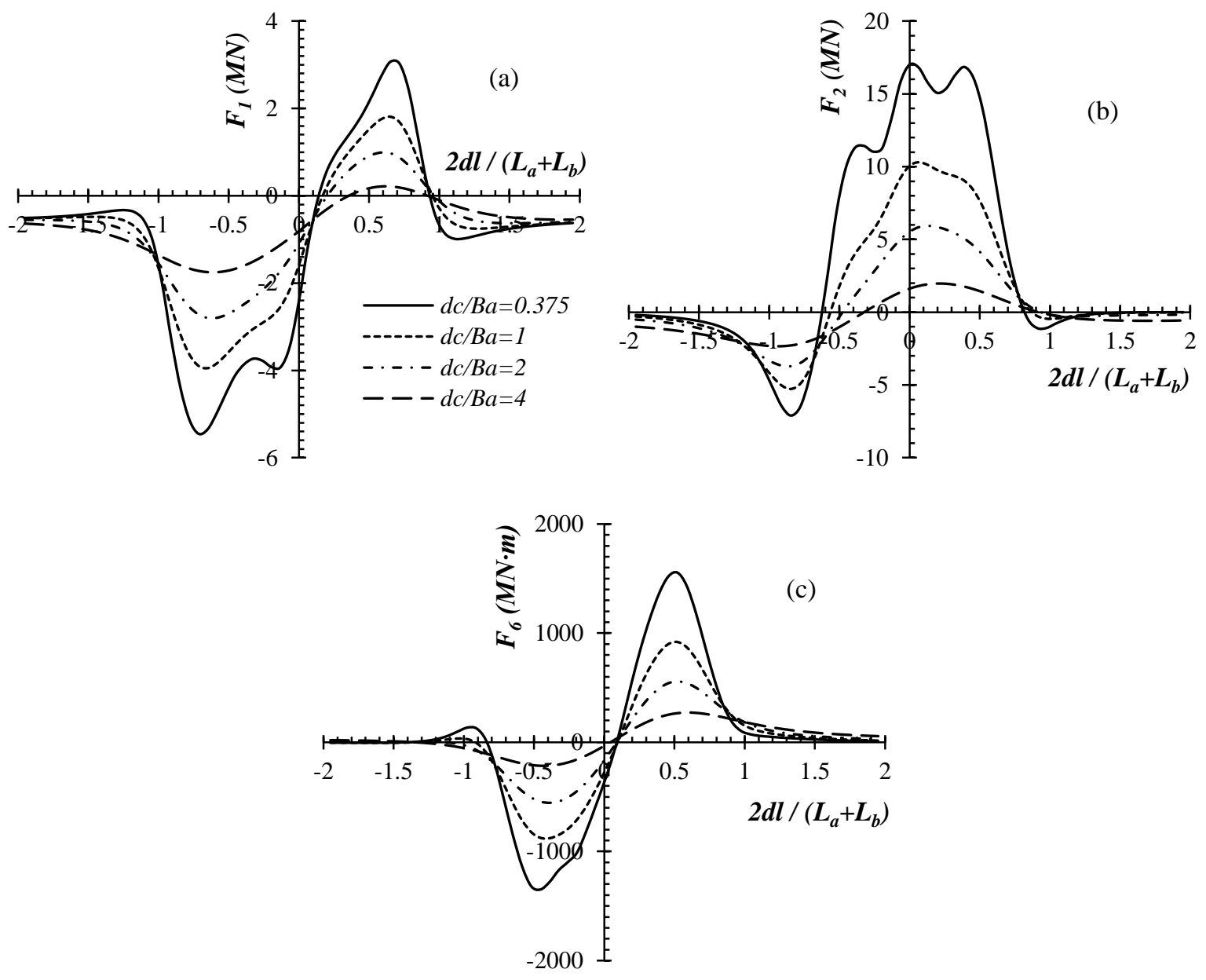

Figure 16 (a) The resistance, (b) the sway force and (c) the yaw moment acting on Model E overtaken by Model C at different transverse distances. $d c$ is the clearance between two ships, and it is defined as $d c=d t-0.5(B a+B b)$.

\section{Numerical simulation of overtaking operation}

In order to investigate the overtaking process, the above-validated uncoupled method will be used in the numerical simulations. Two case studies are simulated here. Case 1: KVLCC2 overtakes Aframax. Case 2: Aframax overtakes KVLCC2. The models used here are exactly the same as those used in Section 3.1. The details of the simulation conditions of Case 1 and Case 2 are shown in Table 4.

Table 4 Simulation conditions of Case 1 and Case 2.

\begin{tabular}{lcc}
\hline & Case 1 & Case 2 \\
\hline Water depth $h(m)$ & 0.374 & 0.374 \\
Draft of KVLCC2 $(m)$ & 0.277 & 0.277 \\
Draft of Aframax $(m)$ & 0.100 & 0.100 \\
Froude number of KVLCC2 & 0.1 & 0.05 \\
Froude number of Aframax & 0.05 & 0.1 \\
Transverse distance $d t(m)$ & 0.9995 & 0.9995
\end{tabular}




\subsection{Force, moment, sinkage and trim}

Figure 17 is the result of the force, moment, sinkage and trim of both ships. The superscript $\boldsymbol{a}$ in Figure 17 denotes KVLCC2, and $\boldsymbol{b}$ denotes Aframax. The longitudinal distance is non-dimensionalized by ship length of Aframax. The negative $x$ values in Case 1 represent that KVLCC2 is downstream of Aframax, where the reference coordinate system is located at midships of Aframax. The positive $x$ values in Case 1 represent that KVLCC2 has overtaken Aframax and is upstream of Aframax. Similarly, in Case 2, the negative $x$ values indicate that Aframax is downstream of KVLCC2, where the reference coordinate system is located at midships of KVLCC2. From Figure 17 (a) it can be observed that the wave-making resistance on each ship is opposite in Case 1 and Case 2. In Case 1, when KVLCC2 is downstream of Aframax, a positive wave-making resistance can be observed on KVLCC2, while on Aframax it is negative. This can be explained by the pressure distribution. When a single vessel is moving in calm water there is a positive pressure field created at the bow, a smaller positive pressure field at the stern and a negative pressure field amidships, as shown in Figure 9 (a). According to Eq. (12), the sign of the wave-making resistance is determined by the pressure integral over the wet hull. At the amidship region, the normal vector in the $x$ direction is almost zero, and the contribution of the amidship region to the wave-making resistance can be neglected. At the bow area, the normal vector in the $x$ direction is negative, which leads to a negative wave-making resistance. At the stern area, the normal vector in the $x$ direction is positive, which leads to a positive wave-making resistance. But as mentioned above, the pressure field at the bow is larger than that at the stern. Therefore, for a single vessel case, the wavemaking resistance is always negative. However, the pressure fields can be significantly changed where the flow of water round the vessel is influenced by the presence of another vessel. In Case 1, when KVLCC 2 is downstream of the Aframax model, the wake produced by Aframax will modify the flow field at the bow of KVLCC2. This phenomenon is called blockage effect (Santo et al., 2014; Taylor, 1991). As a result, the pressure integral at the stern area will be larger than that at the bow area of Aframax, and it becomes apparent that the wave-making resistance on KVLCC2 will be positive. This positive wave-making resistance can be referred as a drag force, which drives KVLCC2 forward. This phenomenon can also be observed in some biomechanical studies about the fish swimming (Liao, 2003; Liao et al., 2003), for example, a dead fish is propelled upstream in the wake of a bluff cylinder, despite being well outside the suction region of the cylinder (Beal et al., 2006). However, as KVLCC2 overtakes Aframax from the downstream side to the upstream side, the drag force gradually reduces towards the negative $y$-axis. When KVLCC 2 is upstream of Aframax, the wake produced by KVLCC 2 could modify the pressure distribution over the Aframax model, and the wave-making resistance of Aframax will be reduced. During the overtaking process, the trend of the wave-making resistance on KVLCC2 is opposite to that on Aframax. It can be concluded that the wave-making resistance could be minimized 
if the ship is located in the wake of the other one. As for the ship being overtaken, it has first to exert appreciably more ahead power than it would use in open water to maintain the same speed and this effect is strongest when it is "off the shoulder" of the other vessel. But after it has been overtaken, the reverse occurs, the ship ahead will produce a drag force and less ahead power is required.

It can be observed from Figure 17 (b) that the trend of the sway forces in each case is opposite on KVLCC2 and Afamax. In Case 1, when KVLCC2 is downstream of Aframax, the sway force on KVLCC2 is positive, while on Aframax it is negative. It could result in a repulsion force, pushing the two ships apart. This repulsion decreases as KVLCC2 approaches Aframax. When the two ships are in a side-by-side arrangement $(d l=0)$, the sway force on KVLCC2 becomes negative, while on Aframax it becomes positive. This could result in an attraction force, causing these two ships to collide with each other. As KVLCC2 overtakes Aframax, the attraction force changes into the repulsion force gradually. A similar phenomenon can also be observed in Case 2. Here the difference is that in Case 2, the repulsion force is smaller, while the attraction force is larger.

From Figure 17 (c) it can be seen that the sinkage of Aframax (the smaller ship) is significantly influenced by the presence of KVLCC2, while the sinkage of KVLCC2 (the larger ship) can be hardly influenced by the presence of Aframax. Since the forward speed of KVLCC2 in Case 1 is larger than that in Case 2, the sinkage of KVLCC2 in Case 1 is much larger. It indicates that the forward speed could influence the sinkage significantly. It can also be observed that the sinkage of both ships increases as the longitudinal distance $(d l)$ becomes smaller, with KVLCC2 located either downstream or upstream. Peak sinkage appears when these two ships are in a side-by-side arrangement $(d l=0)$, and as this is the most dangerous situation, the squat should be taken into consideration in shallow water.

Figure 17 (d) shows the roll moments on both ships in Case 1 and Case 2. The trend of the roll moments is very similar to that of the sway forces. There are two dangerous situations. Either $d l / L_{b} \approx \pm 1$ or $d l /$ $L_{b} \approx 0$ will lead to a large moment, which may result in capsizal. For a single ship case, the roll moment is zero due to the symmetry of the geometry. Because of the presence of the other ship, the symmetrical pressure distribution at the port side and starboard side has been violated, and hence the roll moment is inevitable.

Figure 17 (e) gives the trim results for both ships in Case 1 and Case 2. It can be observed that the fluctuation of the trim curve of the smaller ship (Aframax) is more violent than that of the larger one (KVLCC2). The maximum trim can be found at $d l / L_{b} \approx \pm 0.5$, where the danger of grounding in the stern or bow area has to be taken into consideration in shallow water. Since the forward speed of KVLCC2 in Case 1 is larger than that in Case 2, the trim of KVLCC2 in Case 1 is much larger. It indicates that the forward speed could influence the trim significantly.

Figure 17 (f) shows the results of the yaw moment in Case 1 and Case 2. Similarly to wave-making resistance and trim curves, the four curves in Figure 17 (f) are almost centrally symmetrical, which 
means the yaw moment approaches zero at $d l / L_{b}=0$. In both cases, the peak yaw moment appears at $d l / L_{b} \approx \pm 0.5$. In Case 1 , the yaw moment on both ships is negative at $d l / L_{b} \approx-0.5$. But the absolute value of yaw moment on KVLCC2 is much larger than that on Aframax. One possible outcome is that KVLCC2 may take a sheer into the path of Aframax. At $d l / L_{b} \approx 0.5$ in Case 1, the yaw moment on both ships is positive. But the yaw moment on KVLCC2 is much larger, which will tend to deflect Aframax's bow and attract KVLCC2's stern. Similar observation can also be found in Case 2.
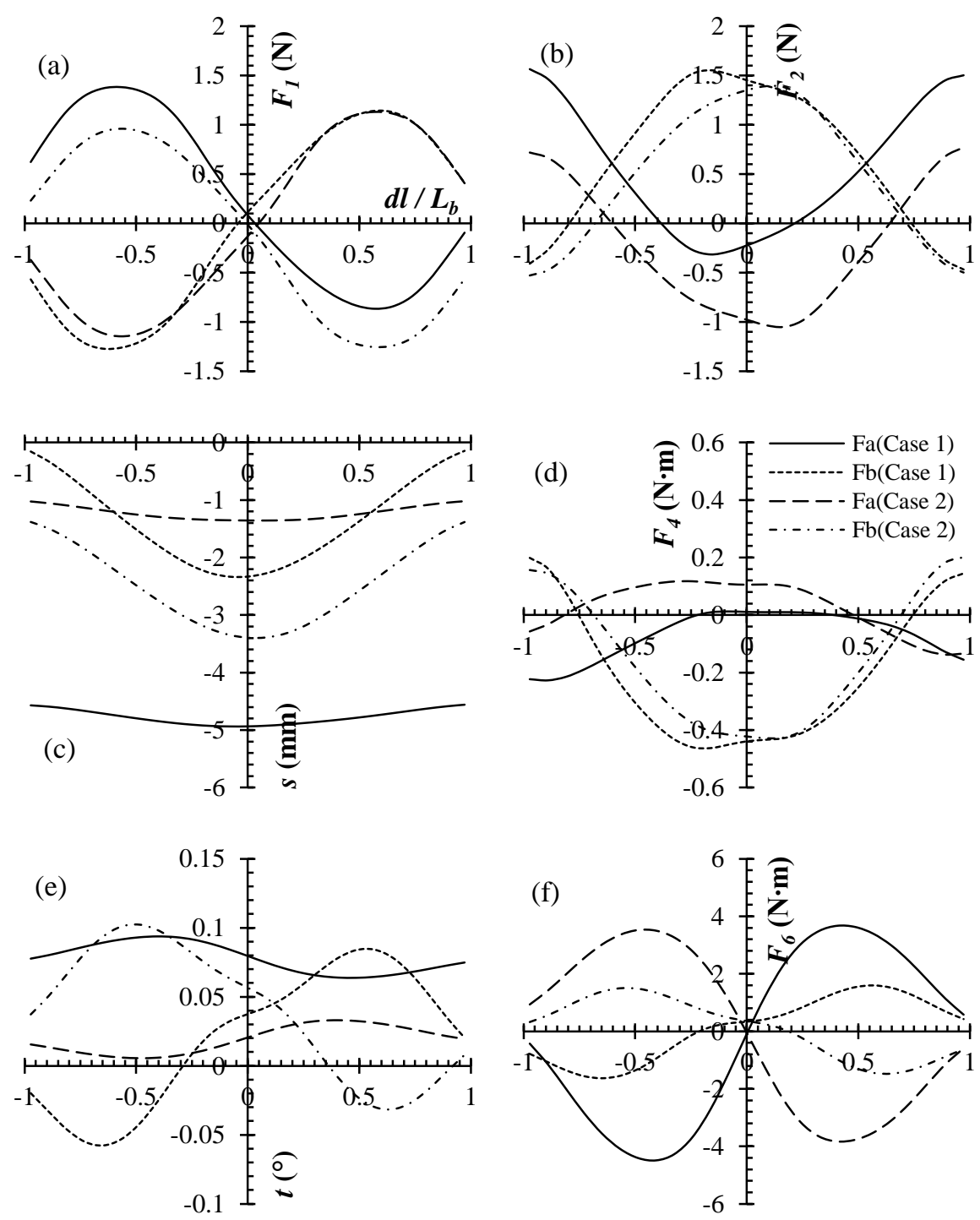

Figure 17 Numerical results of Case 1 and Case 2. (a) Resistance; (b) sway force; (c) sinkage; (d) roll moment; (e) trim; (d) yaw moment.

\subsection{Wave patterns}

Figure 18 and Figure 19 show the wave patterns produced by the ships during an overtaking process. As discussed above, when a single vessel is moving in the calm water, the flow of water round the vessel is symmetrical about the $x$-axis due to the symmetry of the hull geometry. Therefore, there is no generated sway force, roll and yaw moment. But as can be seen from Figure 18 and Figure 19, the symmetrical flow at the port and starboard sides has been violated due to the presence of the other ship. 
This asymmetric phenomenon is particularly evident for the smaller ship, which is overtaken by a larger one, as shown in Figure 18. Consequently, it may cause green water problems or capsizal of the smaller ship. The results in Figure 18 and Figure 19 can explain the reason for the non-zero loads in the sway, roll and yaw directions in Figure 17.

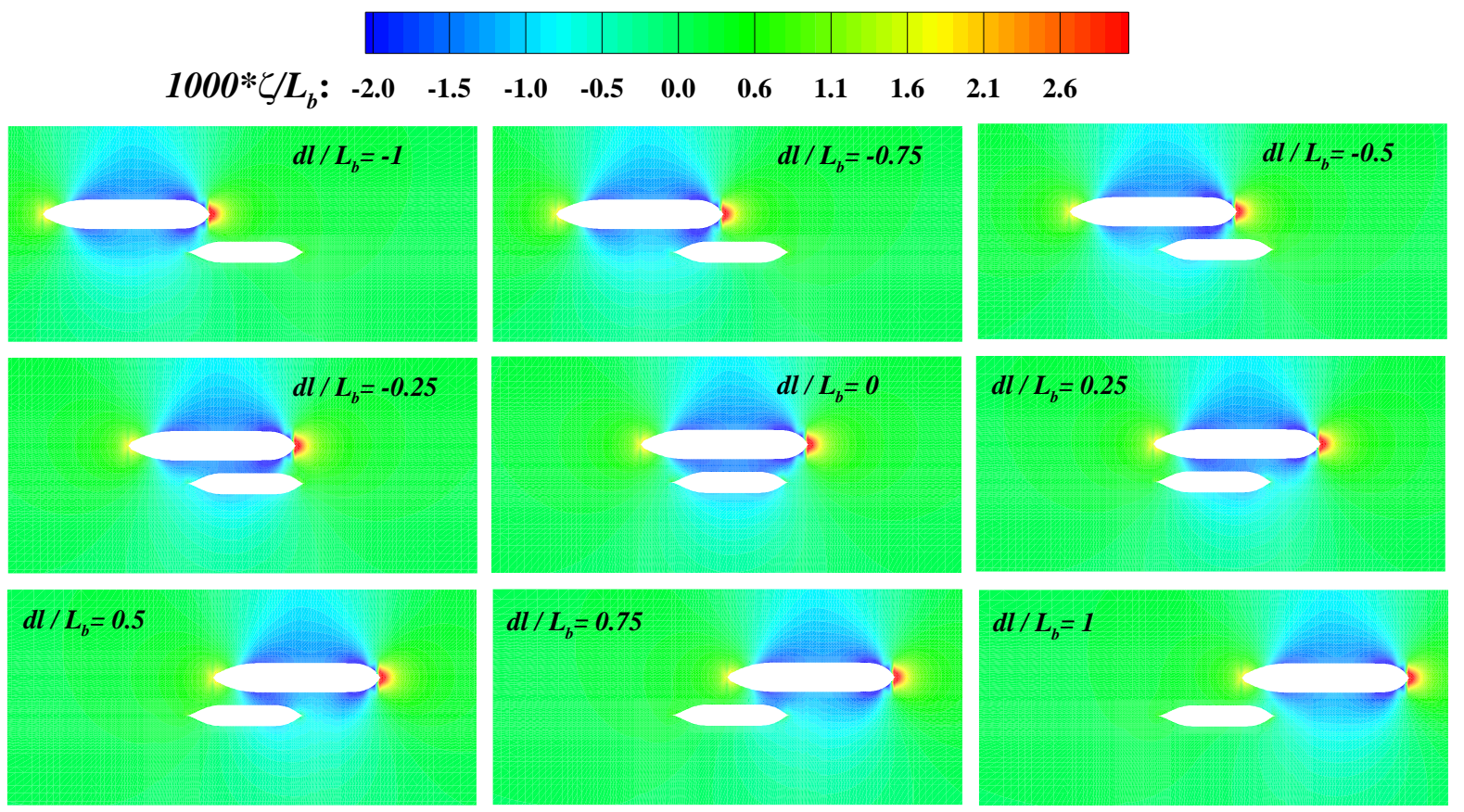

Figure 18 Wave patterns during overtaking process of Case 1 (KVLCC2 overtakes Aframax).

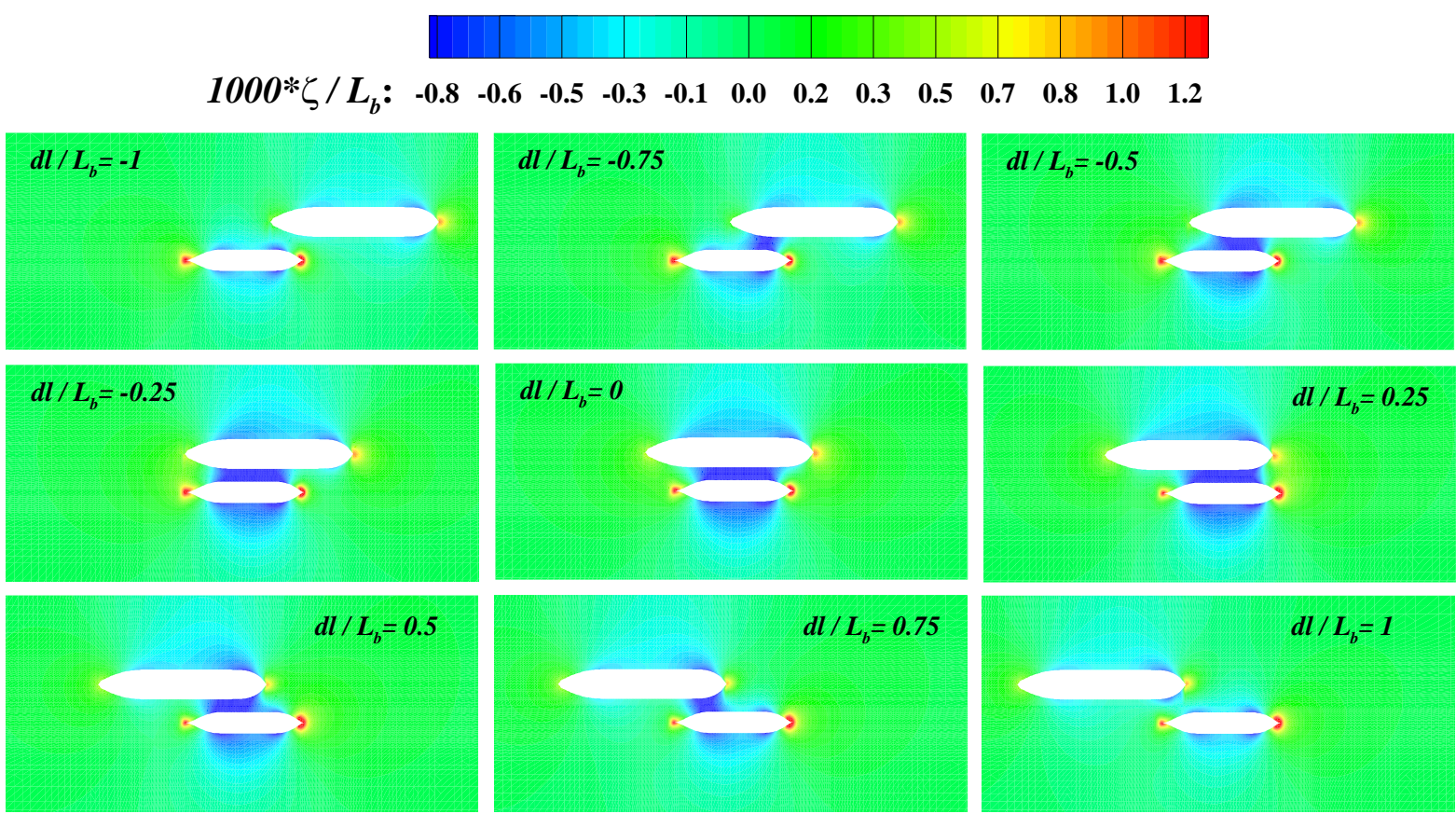

Figure 19 Wave patterns during overtaking process of Case 2 (Aframax overtakes KVLCC2). 


\subsection{Influence of the forward speed}

From Figure 17 we find that the most dangerous situations during an overtaking process are most likely to occur at $d l / L_{b}=0, d l / L_{b} \approx \pm 0.5$ and $d l / L_{b} \approx \pm 1$. In order to investigate the influence of the speed, the three most dangerous situations $\left(d l / L_{b}=0,-1\right.$ and -0.5$)$ are simulated here, which are listed in Table 5. The Froude number of Aframax is fixed at 0.05, while the Froude number of KVLCC2 varies from 0 to 0.2 . The simulation results are shown in Figure 20.

Table 5 Simulation conditions of Case 3, Case 4 and Case 5.

\begin{tabular}{lccc}
\hline & Case 3 & Case 4 & Case 5 \\
\hline Water depth $h(m)$ & 0.374 & 0.374 & 0.374 \\
Draft of KVLCC2 $(m)$ & 0.277 & 0.277 & 0.277 \\
Draft of Aframax $(m)$ & 0.100 & 0.100 & 0.100 \\
Froude number of KVLCC2 & $0 \sim 0.2$ & $0 \sim 0.2$ & $0 \sim 0.2$ \\
Froude number of Aframax & 0.05 & 0.05 & 0.05 \\
Transverse distance $d t(m)$ & 0.9995 & 0.9995 & 0.9995 \\
$d l / L_{b}$ & 0 & -1 & -0.5 \\
\hline
\end{tabular}

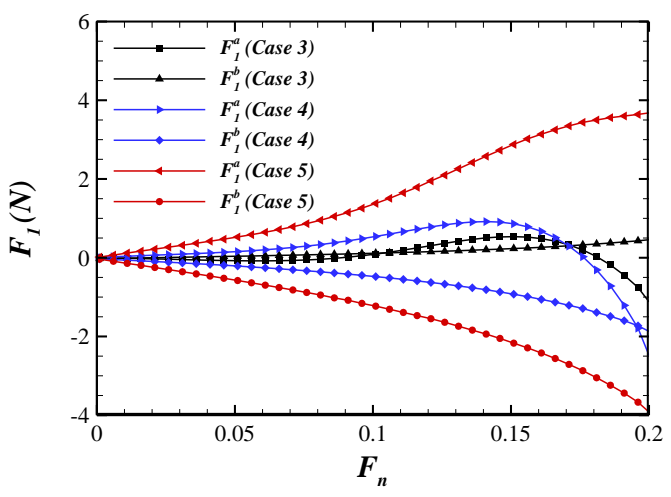

(a)

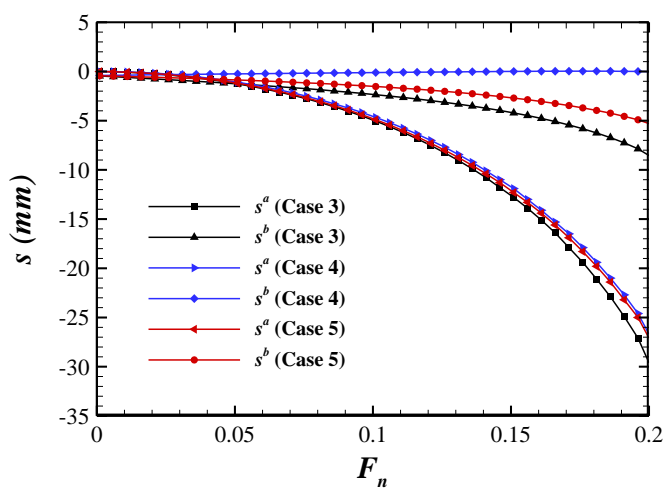

(c)

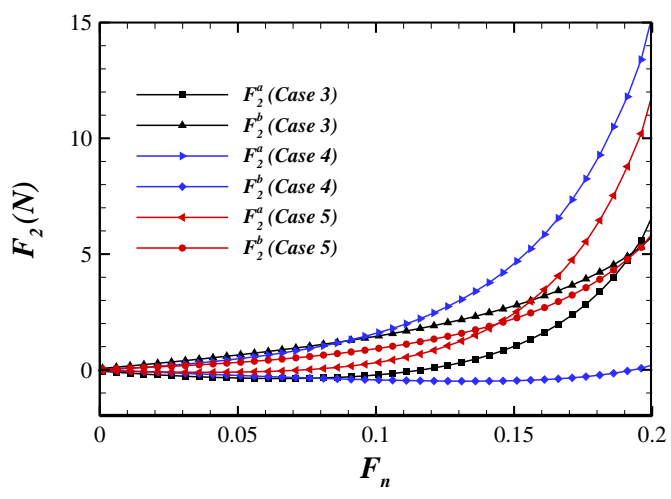

(b)

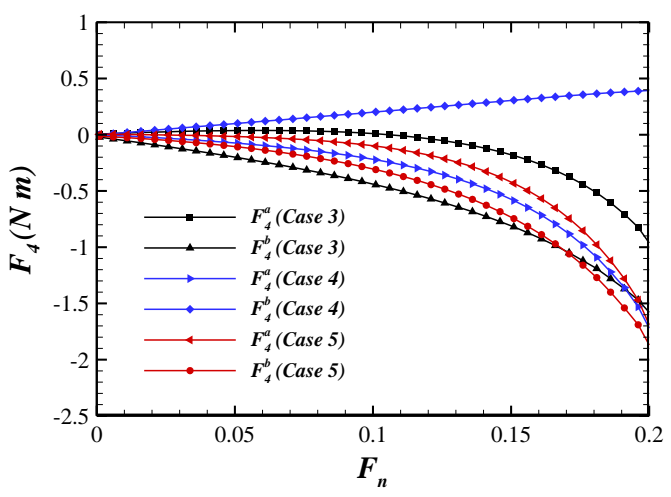

(d) 


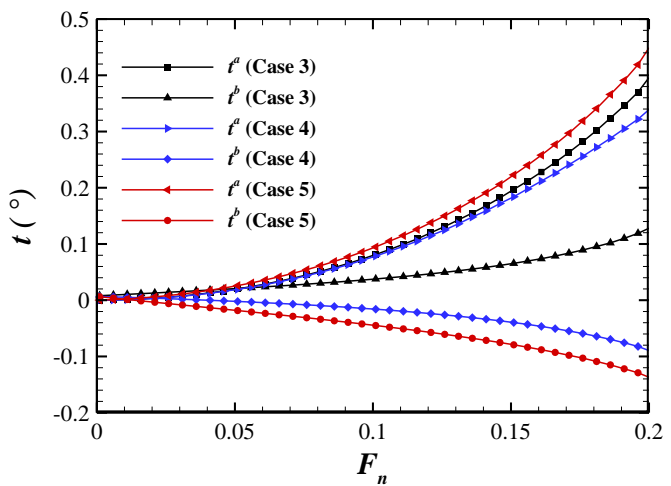

(e)

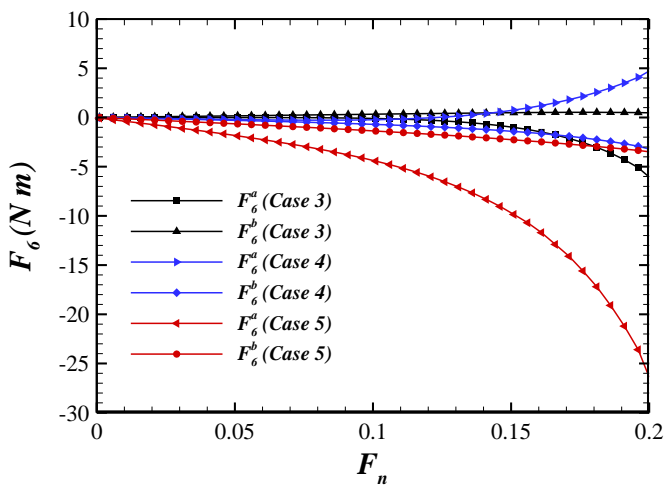

(f)

Figure 20 Numerical results of Case 3, Case 4 and Case 5.

Figure 20 (a) shows the wave-making resistance. The maximum wave-making resistance arises in Case 5, which is consistent with the result in Figure 17 (a). In Case 3 and Case 4, the wave-making resistance increases firstly against the Froude number, and then there is a strong tendency to decrease towards the negative $y$-axis. It is very interesting to find that in Case 5, the wave-making resistance of KVLCC2 is always positive, and as the Froude number of KVLCC2 increases, the wave-making resistance will increase rapidly. KVLCC2 may well drive itself forward under this positive wave-making resistance unless the helm (which will have been put towards the vessel to counter the previous effect) is immediately reversed and engine revolutions rapidly reduced. But in the case of Aframax, the reverse occurs. In Case 5, as the speed increases, the wave-making resistance of Aframax increases towards the negative $y$-axis rapidly. Since the forward speed of Aframax remains constant during the overtaking process, the change in the wave-making resistance of Aframax is only caused by the hydrodynamic interaction. This hydrodynamic interaction is influenced by the forward speed significantly.

It can be observed from Figure 20 (b) that the sway forces on both ships are influenced by the speed significantly as well. Case 4 and Case 5 are the most dangerous cases, which coincide with the results in Figure 17 (b). In Case 4, the sway force on KVLCC2 is always positive, and as the forward speed increases the sway forces will increase dramatically. But on Aframax, the sway force firstly increases with speed towards the negative $y$-axis until $F_{n}=0.15$. Then the trend is reversed and the sway force becomes positive at $F_{n}=0.2$. It means at $F_{n}<0.2$, there exists a strong repulsion force between the two ships, which means they tend to repel each other as they approach. As the speed of KVLCC2 increases, this repulsion force could be very large which may cause KVLCC2 to deviate from its course. In Case 3 and Case 5, if $F_{n}>0.1$, the sway forces on both ships are positive. If no actions are taken from the rudder, these two ships may deviate from their courses anti-clockwise.

Figure 20 (c) and Figure 20 (e) show the results of the sinkage and trim. The difference of the sinkage and trim of KVLCC2 between these three cases is very small. But when it comes to Aframax, a very large discrepancy can be observed between these three cases. It coincides with the results in Figure 17 (c) and Figure 17 (e) that the smaller ship is more easily influenced by the hydrodynamic interaction. It 
can also be found that both the sinkage and trim will increase rapidly with the forward speed. In the shallow water, particular attention should be paid to the squat and risk of grounding. Due to the large trim at $F_{n}=0.2$, the grounding of the bow of KVLCC2 is most likely to occur. The displacement of a point in the base line of the bow can be estimated by

$$
D_{a}^{b o w}=s_{a}+\frac{1}{2} L_{a} \cdot \tan \left(t_{a}\right)
$$

It can be calculated that at $F_{n}=0.2$ in Case $3, D_{a}^{\text {bow }}=45 \mathrm{~mm}$. There is a strong tendency to increase to a larger value as $F_{n}>0.2$. Considering the distance between the base line of KVLCC2 and the sea bottom is only $97 \mathrm{~mm}$, the speed of KVLCC2 may have to be restricted.

From the results in Figure 20 (d) it can be found that the roll moment also increases dramatically against the speed. The most dangerous cases are Case 3 and Case 5. Even though the speed of Aframax keeps constant during the overtaking process, the increase of speed of the passing ship could bring a significant influence on the ship being overtaken. It can be concluded that the smaller ship is more likely to be capsized during the overtaking process.

Figure 20 (f) shows the yaw moment against the Froude number $F_{n}$. The speed effect is also very important. As the speed increases, a very large yaw moment can be observed in Case 5 on KVLCC2. The consequence is that KVLCC2's bow may be strongly attracted by Aframax's stern if the maximum moment provided by the rudder is not sufficient to maintain control adequately. There are many accidents during overtaking operations caused by this reason.

\section{Conclusions}

Situations involving hydrodynamic interaction between vessels vary. The geometry of the vessels, the transverse and longitudinal distance between the vessels, the water depth and the forward speed will be integrated together, making the overtaking problem very complex. In the present study, we proposed an uncoupled method, as well as discussed the development of a numerical program, to predict the ship-toship interaction during an overtaking operation in shallow water. The validations were carried out. Very good agreement has been achieved between the present calculations and the experimental measurements. Systematic numerical studies were conducted to investigate the forces, moments, sinkage and trim during the overtaking process. The discussion also highlighted the speed effect.

When vessels are overtaking at close proximity for operational reasons, the greatest potential danger exists when there is a large difference in size between the two vessels. A dangerous situation is most likely when the smaller ship, having been manoeuvring alongside the larger one, moves ahead to the bow to overtake. Due to changes in drag effect, especially in shallow water, it has first to exert appreciably less ahead power than it would use in open water to maintain the same speed and this effect 
is strongest when it is "off the shoulder". At that point, the maximum yaw moment occurs, which tends to deflect the smaller ship's bow away from the larger one and attract its stern. The rudder has to be immediately adjusted to produce a reversed moment. But as the smaller ship draws ahead the reverse occurs, the stern being strongly attracted, and the strong drag force disappears. The angle of the rudder has to be reversed and more ahead power is required than it would use in open water to maintain the same speed. A further effect of interaction arises from the flow around the larger vessel acting on the underbody of the smaller vessel causing a consequent decrease in effective stability, and thus increasing the likelihood of capsize if the vessels come into contact with each other.

There are two ways to minimize the hydrodynamic interaction: increase the clearance and reduce the speed. As the clearance between two ships increases, the hydrodynamic interactive forces and moments decrease rapidly. However, in some confined waterways, it is impossible to increase the clearance due to the bank effects. In this case, the alternative solution to minimize the hydrodynamic interaction is to reduce the speed. Since it has been found that the hydrodynamic interaction increases dramatically against the forward speed during the overtaking process, this type of manoeuvre should always be carried out at very slow speed. A low speed will lessen the increase in draught due to squat as well as the sinkage and change of trim caused by interaction itself. When vessels are approaching each other at this limiting speed interaction effects will be magnified, therefore a further reduction in speed may be necessary. Those in charge of the handling of small vessels should appreciate that more action may be required on their part when passing large vessels which may be severely limited in the action they can take in shallow water. If vessels of dissimilar size are to work in close company at any higher speeds then it is essential that the smaller one keeps clear of the hazardous area off the other's bow and shoulder. Regardless of the relative size of the vessels involved, an overtaking vessel should only commence an overtaking manoeuvre after the vessel to be overtaken has agreed to the manoeuvre.

\section{Acknowledgments}

The work reported in this paper was performed within the project "Energy Efficient Safe Ship Operation (SHOPERA)" funded by the European commission under contract No. 605221.

\section{References}

Beal, D.N., Hover, F.S., Triantafyllou, M.S., Liao, J.C., Lauder, G.V., 2006. Passive propulsion in vortex wakes. Journal of Fluid Mechanics 549 (-1), 385.

Brix, J., 1993. Manoeuvring technical manual, Seehaveb Verlag, Hamburg.

Chen, G.R., Fang, M.C., 2001. Hydrodynamic interactions between two ships advancing in waves. Ocean Engineering 28, 1053-1078.

Chen, H.C., Lin, W.M., Hwang, W.Y., 2002. Validation and application of chimera RANS method for ship-ship interactions in shallow water and restricted waterway, 24th Symposium on Naval Hydrodynamics, Fukuoka, Japan. 
Fang, M.C., Kim, C.H., 1986. Hydrodynamically coupled motions of two ships advancing in oblique waves. Journal of Ship Research 30 (3), 159-171.

Gourlay, T., 2009. Sinkage and trim of two ships passing each other on parallel courses. Ocean Engineering 36, 1119-1127.

Lataire, E., Vantorre, M., Delefortrie, G., 2009. Captive model testing for ship to ship operations, MARSIM 2009, Panama City, Panama.

Lataire, E., Vantorre, M., Delefortrie, G., Candries, M., 2012. Mathematical modelling of forces acting on ships during lightering operations. Ocean Engineering 55, 101-115.

Liao, J.C., 2003. The Karman gait: novel body kinematics of rainbow trout swimming in a vortex street. Journal of Experimental Biology 206 (6), 1059-1073.

Liao, J.C., Beal, D.N., Lauder, G.V., Triantafyllou, M.S., 2003. Fish exploiting vortices decrease muscle activity. Science 302, 1566-1569.

MCA, 2002. Marine guidance note: dangers of interaction. MGN199 (M).

Müller, E., 1967. Untersuchungen über die gegenseitige Kursbeeinflussung von Schiffen auf Binnenwasserstrassen. Schiff und Hafen 6, 393-406.

Newman, J.N., 1976. Linearized wave resistance, International Seminar on Wave resistance, Tokyo. Newton, R.N., 1960. Some notes on interaction effects between ships close aboard in deep water, First Symposium on Naval Maneuverability, Washington DC, pp. 1-24.

Santo, H., Taylor, P.H., Bai, W., Choo, Y.S., 2014. Blockage effects in wave and current: 2D planar simulations of combined regular oscillations and steady flow through porous blocks. Ocean Engineering $88(0), 174-186$.

Schultz, M.P., 2007. Effects of coating roughness and biofouling on ship resistance and powering. Biofouling 23 (5-6), 331-341.

Söding, H., Conrad, F., 2005. Analysis of overtaking manoeuvres in a narrow waterway. Ship Technology Research 52, 189-193.

Taylor, P.H., 1991. Current blockage: reduced forces on offshore space-frame structures, Offshore Technology Conference, OTC6519.

Tuck, E.O., Newman, J.N., 1974. Hydrodynamic interactions between ships, Proceedings of 10th Symposium on Naval Hydrodynamics, Cambridge, MA, USA, pp. 35-70.

Vantorre, M., Verzhbitskaya, E., Laforce, E., 2002. Model test based formulations of ship-ship interaction forces. Ship Technology Research 49, 124-141.

Varyani, K.S., McGregor, R., Wold, P., 1998. Interactive forces and moments between several ships meeting in conPned waters. Control Engineering Practice 6, 635-642.

Varyani, K.S., McGregor, R., Wold, P., 2002. Identification of trends in extremes of sway-yaw interference for several ships meeting in restricted waters. Ship Technology Research 49, 174191.

Wang, H.-Z., Zou, Z.-J., 2014. Numerical study on hydrodynamic interaction between a berthed ship and a ship passing through a lock. Ocean Engineering 88 (0), 409-425.

$\mathrm{Xu}, \mathrm{X}$., Faltinsen, O.M., 2011. Time domain simulation of two interacting ships advancing parallel in waves, Proceedings of the 30th International Conference on Offshore Mechanics and Arctic Engineering, Rotterdam, The Netherlands, pp. OMAE2011-49484.

$\mathrm{Xu}, \mathrm{Y}$., Dong, W.C., 2013. Numerical study on wave loads and motions of two ships advancing in waves by using three-dimensional translating-pulsating source. Acta Mechanica Sinica 29 (4), 494-502.

Yeung, R.W., 1978. On the interactions of slender ships in shallow water. Journal of Fluid Mechanics 85, 143-159.

Yuan, Z.M., Incecik, A., Day, A., 2014a. Hydrodynamic interactions between two ships travelling or stationary in shallow waters. Submitted to Ocean Engineering.

Yuan, Z.M., Incecik, A., Day, A., 2014b. Verification of a new radiation condition for two ships advancing in waves. Applied Ocean Research 48, 186-201.

Yuan, Z.M., Incecik, A., Jia, L., 2014c. A new radiation condition for ships travelling with very low forward speed. Ocean Engineering 88, 298-309.

Zou, L., Larsson, L., 2013. Numerical predictions of ship-to-ship interaction in shallow water. Ocean Engineering 72, 386-402. 
